Dossiê "Saúde única: Democratizando ciências, aprendizados e práticas"

Eixo temático: Saúde única e seus saberes

\title{
O uso do Instagram como ferramenta de auxílio ao combate às Fake News na Saúde Única
}

\section{The use of Instagram as a tool to help the fight of Fake News at One Health}

\author{
Laís Mendes Batista Costa*, Roberta Lemos Freire, Eloiza Teles Caldart
}

\begin{abstract}
${ }^{1}$ Universidade Estadual de Londrina-UEL, Londrina-PR, Brasil, 86057-970, *lais.mendes.batista.costa@uel.br, http://orcid.org/0000-0002-9162-186X (autora correspondente); rlfreire@uel.br; http://orcid.org/0000-0001-8522-035X; eloizacaldart@uel.br, http://orcid.org/0000-0002$\underline{0475-2010}$
\end{abstract}

\section{Resumo}

Atualmente, na era da internet, possuímos todo o tipo de informação a apenas um clique; entretanto, nem sempre essa agilidade é benéfica. Muitas vezes, nos deparamos com notícias falsas sobre os mais variados assuntos, compartilhados de forma intencional, com a finalidade de prejudicar algo ou alguém, ou de forma ingênua, devido ao não conhecimento sobre o assunto. No que tange a ciência, as mais variadas Fake News já foram descritas e continuam a ser disseminadas, principalmente no atual momento de pandemia, em que além da angústia, gerada pelo isolamento social e medo da doença, as pessoas passaram a utilizar as redes sociais por mais tempo. Devido a este cenário, o Grupo de Estudos em Parasitologia e Saúde Pública (GESPP) da UEL objetivou contribuir com o combate às Fake News relacionadas à Medicina Veterinária através da divulgação de conteúdos simples e didáticos, realizados com embasamento e discussão científica, por meio da rede social Instagram; para isto, foi utilizada a metodologia de pesquisa-ação e pudemos concluir que, mesmo em fase inicial, nosso projeto é de fundamental importância na política de combate às Fake News e na disseminação do conteúdo científico, além de ser um alicerce na implementação da Saúde Única.

Palavras-chave: rede social, ensino, mitos, ciência. 


\begin{abstract}
Today, in the internet age, we have all kinds of information just a click away; however, this agility is not always beneficial. Often, we come across false news on a variety of subjects, shared intentionally, with the purpose of harming something or someone, or naively, due to lack of knowledge about the subject. Regarding science, the most varied Fake News have already been described and continue to be disseminated, especially in the current moment of pandemic, in which, in addition to the anguish generated by social isolation and fear of the disease, people started to use social networks longer. Due to this scenario, the Study Group in Parasitology and Public Health (GESPP) aimed to contribute to the fight against Fake News related to Veterinary Medicine through the dissemination of simple and educational content, carried out with scientific basis and discussion, through the Instagram social midia. For this, the research-action methodology was used and, even in the initial phase, our project is of fundamental importance in the policy of combating Fake News and in the dissemination of scientific content, therefore, it helps the implementation of the One Health.
\end{abstract}

Keywords: social network, teaching, myths, science.

\title{
1. Introdução
}

Atualmente, a internet, sobretudo as redes sociais digitais, são determinantes para a rapidez, facilidade e dinamismo com que as notícias são fabricadas e distribuídas. Em questão de segundos estamos à par de informações de qualquer parte do mundo; contudo, essa fluidez de elementos nem sempre é benéfica ou verídica. A definição de Fake News dada por Lazer et al. (2018), consiste na fábrica de informações que mimetizam fonte jornalística, mas carecem das normas e processos editoriais da mídia para garantir a credibilidade das informações. Fake News são identificadas, hoje, como sintoma de um quadro amplo de desordens informacionais.

De acordo com Wardle \& Derakhshan (2018), isso inclui a informação incorreta 'misinformation', referente a informações que são compartilhadas porque alguém que acredita que são verdadeiras, sem o objetivo de causar dano; a informação falsificada 'disinformation' ou informações falsas que são compartilhadas intencionalmente, com objetivo de causar dano; e a má informação 'malinformation', informação genuína, em geral da esfera privada, que é compartilhada para causar dano a uma pessoa, Instituição ou País.

No que tange a ciência, podemos encontrar uma associação desses quadros, exemplificada 
durante o atual período de combate à pandemia da COVID-19, em que hipóteses são divulgadas como verdadeiras sem que haja consenso científico para tal. Devido aos inúmeros compartilhamentos, a Organização das Nações Unidas para a Educação, a Ciência e a Cultura (UNESCO) utilizou uma campanha de hashtags (\#ThinkBeforeClicking, \#ThinkBeforeSharing e \#ShareKnowledge) incentivando a população a não compartilhar dados duvidosos ou, ao menos, a pensar antes de divulgá-los (UN News, 2020).

Neste contexto, a internet, também é capaz de gerar opiniões e comportamentos sociais que podem colocar em risco a saúde pública (Lara-Navarra et al., 2020; Moscadelli, 2020). Todavia, vale ressaltar que, várias outras pandemias de doenças zoonóticas e doenças infecciosas (re) emergentes são originadas dos animais (Christou, 2011), o que indica uma ameaça não só à saúde humana, mas à Saúde Única como um todo.

A importância deste problema foi ilustrada pela Organização Mundial da Saúde (OMS), que alertou sobre a possibilidade de a atual pandemia tornar-se uma "infodemia", devido a disseminação rápida e abrangente de informações precisas e imprecisas. Moscadelli et al. (2020), lembram ainda que, durante o período de isolamento social, a população passou a utilizar a internet e as redes sociais por mais tempo e, consequentemente, o impacto do compartilhamento de informações falsas foi maior que o habitual. Paralelamente, a repetição constante de Fake News traz uma falsa sensação de familiaridade ao leitor, resultando em uma grande aceitação da propagação da informação (Pennycook \& Rand, 2018). Como agravante deste cenário, Vosoughi et al. (2018) alertam que notícias falsas são tipicamente compartilhadas por mais pessoas, mais vezes e mais rapidamente no Twitter, Inc. do que informações reais, já que, a novidade e as emoções fazem com que as mentiras se difundam mais rapidamente do que conteúdos verdadeiros.

Dado a enorme quantidade de elementos compartilhados todos os dias, uma pesquisa realizada por Fagundes et al. (2021), revela que os jovens brasileiros, em sua maioria, demonstram insegurança e dificuldade em identificar o que é verdadeiro e em quem confiar quando tratamos de notícias que circulam pela internet e por aplicativos. Ainda de acordo com a autora, a ciência é, na opinião dos jovens, um tema ainda pouco acessível à população, o que 
dificulta a diferenciação entre conteúdos verdadeiros e falsos. Podemos atrelar a isso, a dificuldade de acesso, senso crítico e/ou habilidade linguística suficientes para acesso aos principais meios de divulgação dos achados científicos, caminhando ainda mais para a desigualdade social e intelectual.

Os projetos de pesquisa em ensino da Universidade Estadual de Londrina (UEL) constituem um conjunto de atividade de caráter temporário que visam a reflexão crítica, a análise de concepções e a melhoria do processo ensino/aprendizagem nos cursos de graduação. O Grupo de Estudos em Saúde Pública e Parasitologia (GESPP) da UEL é um projeto de pesquisa em ensino criado em 2013 com o objetivo de oferecer aos seus participantes, atualizações que permitem aprofundar conhecimentos e refletir criticamente sobre temas da medicina veterinária preventiva e saúde pública.

No contexto da pandemia do COVID-19, considerando a dificuldade que a população enfrenta para diferenciar notícias falsas de verdadeiras nas mídias sociais, bem como a importância da participação do médico veterinário na Saúde Única (Kaplan, 2009) - conceito baseado na proteção à saúde pública através de políticas destinadas a prevenir e controlar patógenos animais, considerando a interface entre humanos, animais e o meio ambiente (Gibbs \& Anderson, 2009) - o GESPP modificou sua forma de atuação e passou a contar com encontros nos quais se combatem possíveis notícias falsas com ciência, objetivando auxiliar na contenção da disseminação dessas informações errôneas e promover a expansão do conhecimento científico de forma simples e didática. O objetivo do presente trabalho foi demostrar a metodologia de pesquisa-ação utilizada pelo GESPP no combate a Fake News com ciência, a forma de disseminação desse combate e o resultado obtido até o momento.

\section{Material e Métodos}

A composição do grupo é de quatro professores, 15 alunos de graduação, dentre eles uma bolsista, e de quatro alunos de pós-graduação lato sensu, residentes em saúde pública e em moléstias parasitárias. Os encontros são quinzenais, durante os quais são realizadas discussões sobre as principais Fake News que englobam a Medicina Veterinária, bem como o impacto delas 
na sociedade, com foco principal de combater a informação falsa com argumentação científica. A escolha dos temas é baseada na observação de discussões ocorridas em grupos de redes sociais e/ou aplicativos de mensagens sobre a veracidade de tais informações.

Anteriormente à apresentação e discussão com os ouvintes do grupo, os graduandos, previamente escalados e sempre acompanhados por profissionais e pós-graduandos, realizam busca intensiva de dados, artigos ou notícias, sempre de fontes seguras, que comprovem ou desmistifiquem o tema proposto. Durante o encontro, os alunos fazem a explanação do tema e refutam as informações por meio da pesquisa previamente realizada.

Após realizarmos o encontro e debate acerca do tema, o conteúdo científico é transformado em postagens para a conta do projeto de extensão universitária parceiro @educasaudeunicauel na rede social Instagram em quadro quinzenal denominado "Jornal GESPP - combatendo Fake News com ciência" (Figura 1). As informações são expostas de forma clara e concisa, com linguagem informal, de forma a aproximar seguidores leigos ao conteúdo abordado, já que, a maior parte da população brasileira não possui acesso e/ou conhecimento técnico-científico aos principais acervos confiáveis da ciência.

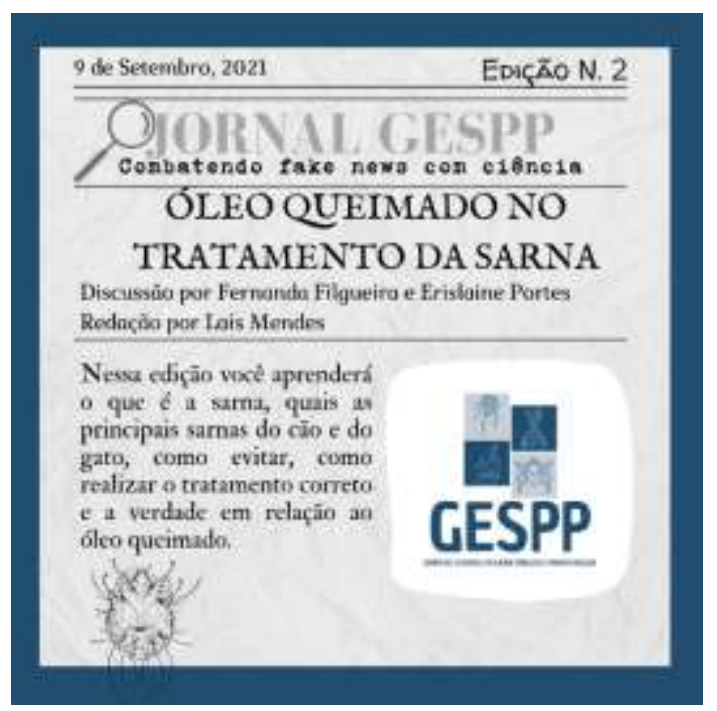

Figura 1. Parte de uma postagem realizada na conta@educasaudeunicauel após a discussão do grupo.

Para conhecer o alcance do conteúdo divulgado no projeto até o dia 20 de outubro de 2021, com auxílio da ferramenta Insights do Instagram, observou-se as seguintes métricas: 
impressões (diz respeito a quantidade de vezes que uma postagem foi vista, sem diferenciar se foi visualizado mais de uma vez por um mesmo usuário), alcance (métrica que contabiliza o número de usuários que tiveram acesso à publicação) e salvamento de publicações (função na qual o usuário pode guardar a publicação em sua galeria pessoal da rede).

\section{Resultados}

Os assuntos já debatidos pelo grupo foram os mitos relacionados: 1- aos maus tratos dos cavalos de hipismo, 2- ao uso do óleo queimado no tratamento da sarna em animais de companhia e 3- ao uso do quiabo para o tratamento da cinomose em cães. Na Tabela 1 são apresentados os temas debatidos e as referências utilizadas.

Tabela 1. Temáticas discutidas nos encontros do GESPP em 2021.

\begin{tabular}{|c|l|}
\hline Tema abordado & \multicolumn{1}{|c|}{ Referências da discussão } \\
\hline Tema 1 & $\begin{array}{l}\text { Broom \& Fraser (2010) } \\
\text { McGeevy (2004) } \\
\text { Meyer \& Hagen (1995) } \\
\text { Mills et al. (2002) }\end{array}$ \\
\hline Tema 2 & $\begin{array}{l}\text { Oliveira (2009) } \\
\text { Fourie et al. (2015) } \\
\text { Castro \& Zimermann (2016) }\end{array}$ \\
\hline Tema 3 & $\begin{array}{l}\text { Kumar et al. (2013) } \\
\text { Esmaeilzadeh et al. (2000) } \\
\text { Freire \& Moraes (2019) } \\
\text { Portela et al. (2017) } \\
\text { Flores (2017) }\end{array}$ \\
\hline
\end{tabular}

Das três postagens realizadas no Instagram (@educasaudeunicauel), obtivemos uma média de 568 impressões, de 407 contas alcançadas e de 5 publicações salvas (Tabela 2). 
Tabela 2. Dados de alcance das publicações do "Jornal GESPP - combatendo Fake News com ciência" no Instagram.

\begin{tabular}{cccc}
\hline Título da publicação & Impressões & $\begin{array}{c}\text { Contas } \\
\text { alcançadas }\end{array}$ & $\begin{array}{c}\text { Salvar } \\
\text { publicação }\end{array}$ \\
\hline Mitos dos cavalos de hipismo & 604 & 409 & 6 \\
$\begin{array}{c}\text { Óleo queimado no tratamento da sarna } \\
\text { em animais domésticos }\end{array}$ & 567 & 419 & 9 \\
$\begin{array}{c}\text { Uso do quiabo para tratamento da } \\
\text { cinomose em cães }\end{array}$ & 538 & 393 & 1 \\
\hline
\end{tabular}

No que tange ao resultado das análises das Fake News, em todas as postagens, além de responder o porquê do assunto abordado seria um mito, pudemos também fornecer informações didáticas complementares relevantes em cada uma das temáticas, facilitando assim, a compreensão do público leigo sobre o assunto (Tabela 3).

Tabela 3. Informações contempladas nas postagens do "Jornal GESPP - combatendo Fake News com ciência"

\section{Título da publicação}

Mitos dos cavalos de hipismo

Óleo queimado no tratamento da sarna em animais domésticos

Uso do quiabo para tratamento da cinomose em cães

\section{Conteúdo}

Cavalos atletas sofrem maus tratos durante as competições? Animais são eutanasiados devido à ausência de valor competitivo? Como são realizadas as fiscalizações de parâmetros durante competições? Como é realizada a reprodução desses animais?

Há alguma comprovação científica do uso do óleo no tratamento? Pode haver intoxicação pelo seu uso? O que é sarna? Quais as principais sarnas que acometem o cão e o gato, como evitá-las e qual o tratamento correto?

Há alguma comprovação científica do uso do quiabo no tratamento? Pode haver intoxicação pelo seu uso? O que é a cinomose, como evitá-la e qual o tratamento correto? 


\section{Discussão}

Dada a problemática envolvida na disseminação das Fake News, fica evidente a necessidade de novas formas de divulgação de temas relacionados à saúde, que aproximem a comunidade às descobertas da ciência. Nesse sentido, os Projetos de Extensão das Universidades tornam-se fundamentais e vão de encontro com o que é discutido por Mamak (2021), que propõe que a ciência deve ser ainda mais acessível nos casos de estudos que são financiados com o dinheiro público.

Devido ao isolamento social atual, o GESPP notou a oportunidade de desmistificar alguns dos mitos mais cotidianos no dia a dia do médico veterinário, de forma simples e descontraída. Considerando que a maior parte da população hoje em dia possui acesso, ainda que limitado, às redes sociais, pretende-se minimizar possíveis ameaças à Saúde Única e o negacionismo à ciência gerado pela disseminação de mitos ou crenças, com as discussões e postagens.

Dubé et al. (2012), reforçam a necessidade da transferência científica pelos profissionais da saúde para a população geral, já que, em sua pesquisa, pôde concluir que os pais que vacinaram seus filhos tendem a ser mais informados sobre as vacinas por profissionais da saúde e menos propensos a procurar informações negligentes na internet, diminuindo assim, o potencial reprodutivo do Movimento Anti-Vacina, que tem ganhado força nos últimos anos.

Vale ressaltar que ao publicarmos essas informações em uma conta pública, com perfil variado de seguidores, podemos atingir um número elevado de pessoas, já que, a postagem pode ser repostada e encaminhada para outras redes sociais, alcançando, inclusive, público não seguidor da conta. Além disso, por tratar-se de uma mídia social informal, os seguidores podem se beneficiar ainda da aprendizagem passiva, já que, quando seguimos uma conta, recebemos seus informes constantemente em momentos distintos do nosso dia.

Por fim, concluímos que, mesmo em fase inicial, nosso projeto é de fundamental importância na política de combate às Fake News e na disseminação do conteúdo científico, devido ao grande alcance das publicações, além de ser um alicerce na propagação da Saúde 
Única, já que empenha-se na prevenção e controle de patógenos animais, bem como na diminuição de tratamentos/ações que podem gerar prejuízos elevados aos animais, humanos e meio ambiente, muito bem evidenciado na discussão denominada "Uso de óleo queimado no tratamento da sarna em animais domésticos". Além disso, as demais políticas que vêm sendo implementadas pelos aplicativos e redes sociais, que visam bloquear e/ou descartar informações errôneas, compõem um elemento de suma importância neste combate e devem ser incentivados.

\section{Referências}

Broom, D. M.; Fraser, A. F. (2010). Comportamento e bem-estar de animais domésticos. 4. ed. Barueri: Manole, p. 438.

Castro, M. \& Zimermann, M.H. (2016). Utilização da fluralaner no tratamento de escabiose em cão: relato de caso. Revista Tecnológica, v. 5, n. 2. p. 198-203, Disponível em: https://uceff.edu.br/revista/index.php/revista/article/view/188

Christou L. (2011). The global burden of bacterial and viral zoonotic infections. Clinical microbiology and infection: the official publication of the European Society of Clinical Microbiology and Infectious Diseases, v. 17, n.3, p. 326-330. https://doi.org/10.1111/j.1469$\underline{0691.2010 .03441 . \mathrm{x}}$

Esmaeilzadeh, D.; Razavi, B. M.; Hosseinzadeh, H. (2020). Effect of Abelmoschus esculentus (okra) on metabolic syndrome: A review. Phytotherapy Research, v. 34, n. 9, p. 2192-2202. https://doi.org/10.1002/ptr.6679

Fagundes, V. O., Massarani, L., Castelfranchi, et al. (2021). Young people's perception about Fake News in science. Boletim Do Museu Paraense Emilio Goeldi:Ciencias Humanas, v. 16, p. 1. https://doi.org/10.1590/2178-2547-BGOELDI-2020-0027

Flores, E. F. (2017). Virologia Veterinária. 3. ed. Santa Maria, Brasil: Editora UFSM. 1136p.

Fourie et al. (2015). Efficacy of orally administered fluralaner (Bravecto ${ }^{\mathrm{TM}}$ ) or topically applied imidacloprid/moxidectin (Advocate ${ }^{\circledR}$ ) against generalized demodicosis in dogs. Parasites \& Vectors, v. 8, n 187. https://doi.org/10.1186/s13071-015-0775-8

Freire, C. G. V. \& Moraes, M. E. (2019). Cinomose canina: aspectos relacionados ao diagnóstico, tratamento e vacinação. Pubvet, $\quad$ v. $13, \quad$ n. $2, \quad$ p. 1-8. https://doi.org/10.31533/pubvet.v13n2a263.1-8

Gibbs, E. P. J. \& Anderson, T. C. (2009). One World - One Health and the global challenge of 
epidemic diseases of viral etiology. Veterinaria Italiana, 45, n.1, p 35-44.

Kaplan, B., Kahn, L. H., \& Monath, T. P. (2009). The brewing storms. Veterinaria italiana, v. 45, n.1, p. 9-18.

Lara-Navarra P, Falciani H, Sánchez-Pérez EA, Ferrer-Sapena A. (2020) Gerenciamento de informações em saúde e meio ambiente: em direção a um sistema automático para detecção de notícias falsas. International Journal of Environmental Research and Public Health; v. 17 p. 1066-1076.

Lazer, D. M. J, Baum, M. A., Benkler Y., et al. (2018). The Science of Fake News. Science, v. 359, n. 6380, p. 1094-1096. https://doi.gor/10.1126/science.aao2998

McGeevy, P. (2004). Equine Behaviour: A guide for Veterinarians and Equine Scientists. Elsevier, 369p.

Meyer, H., \& Hagen, S. (1995). Alimentação de cavalos. Varela.303p.

Mamak, K. (2021). Do we need the criminalization of medical Fake New? Medicine, Health Care and Philosophy, p. 24, v.2, p. 235-245. https://doi.org/10.1007/s11019-020-09996-7

Mills D.S., Alston R.D., Rogers V. \& Longford N. (2002). Factors associated with the prevalence of stereotypic behaviour amongst thoroughbred horses passing through auctioneer sales. Applied Animal Behaviour Science, v. 72, n. 2, p. 115-124. https://doi.org/10.1016/S01681591(02)00096-5

Moscadelli, A., Albora, G., Biamonte, M. A., et al. (2020). Fake News and covid-19 in Italy: Results of a quantitative observational study. International Journal of Environmental Research and Public Health, v. 17(16), p. 1-13. https://doi.org/10.3390/ijerph17165850

Kumar, A. et al. (2013). A review on: Abelmoschus esculentus (Okra). International. Research Journal of Pharmaceutical and Applied Sciences, v. 3, n. 4, p. 129-132.

Oliveira, F. R. M. (2009). Intoxicações em pequenos animais. Monografia. Instituto Politécnico de Viana do Castelo. Escola Superior Agrária de Ponte de Lima, Portugal. 72p. Disponível em: https://consultadogvet.files.wordpress.com/2017/02/tese_1.pdf

Pennycook, G. \& Rand, D. G. (2018). Lazy, not biased: Susceptibility to partisan Fake News is better explained by lack of reasoning than by motivated reasoning. Cognition. https://10.1016/j.cognition.2018.06.011

Portela, V. A. D. B.; de Lima, T. M.; Maia, R. de C. C. (2017). Cinomose canina: revisão de literatura. Medicina Veterinária (UFRPE), v. 11, n. 3, p. 162-171. https://doi.org/10.26605/medvet-n3-1776 
UN News. (2020). During this coronavirus pandemic, 'Fake News' is putting lives at risk: UNESCO. Disponível em: https://news.un.org/en/story/2020/04/1061592. Acessado em: 17 de setembro de 2021.

Vosoughi, S., Roy, D., Aral, S. (2018). The spread of true and false news online. Science, v. 359, n. 6380, p. 1146-1151. https://10.1126/science.aap9559

Wardle, C., \& Derakhshan, H. (2018). Thinking about 'information disorder': formats of misinformation, disinformation, and mal-information. Ireton, Cherilyn; Posetti, Julie. Journalism 'Fake News'\& disinformation. Paris: Unesco, p. 43-54.

\section{Direitos autorais (Copyrights)}

Financiamento: Este trabalho foi financiado pela FAEPE - Fundação de Apoio à Pesquisa e a Extensão, UEL - cadastrado sob o ${ }^{\circ} 865$.

Conflitos de interesse: Todos os autores declaram não haver conflito de interesses.

Aprovação do comitê de ética: Não aplicável.

Disponibilidade dos dados de pesquisa: Os conjuntos de dados gerados e / ou analisados neste estudo não estão disponíveis publicamente devido as políticas de privacidade da plataforma Instagram, uma vez que tratam de informações privadas e confidenciais da conta @educasaudeunicauel, mas poderão ser solicitados ao autor correspondente (Laís Mendes Batista Costa - lais.mendes.batista.costa@uel.br).

Contribuição dos autores: Idealização: Caldart, ET, Freire, RL; investigação/execução da pesquisa e redação/escrita do manuscrito: Costa, LMB, Caldart ET. 